Check for updates

Cite this: RSC Adv., 2019, 9, 28718

Received 25th July 2019

Accepted 4th September 2019

DOI: 10.1039/c9ra05748j

rsc.li/rsc-advances

\section{High acidity cellulose sulfuric acid from sulfur trioxide: a highly efficient catalyst for the one step synthesis of xanthene and dihydroquinazolinone derivatives $\uparrow$}

\author{
Xiaofei Yue, $\$$ Zhiqiang Wu, (DD $\$$ Gang Wang, Yanping Liang, Yanyan Sun, \\ Manrong Song, Haijuan Zhan, Shuxian Bi and Wanyi Liu*
}

A cellulose sulfonate catalyst (HS-cellulose sulfonate) with high stability, excellent catalytic activity and high acidity value (about $1.55 \mathrm{mmol} \mathrm{g}{ }^{-1}$ ) was successfully prepared by $\mathrm{SO}_{3}$ gas phase sulfonation. The basic morphology and nanostructure of the catalyst were determined by HRTEM, XRD, IR, TG, etc. In addition, the catalyst was applied to the catalytic reaction of a dihydroquinazolinone derivative and a xanthene compound, and very valuable results were obtained. The development and preparation of cellulose sulfonate catalysts provide a good approach for the development and application of cellulose, and also an important application of green organic catalytic synthesis methodology.

\section{Introduction}

In recent years, catalysts and reagents containing $-\mathrm{SO}_{3} \mathrm{H}$ have received considerable attention and use in organic synthesis. ${ }^{1-4}$ Examples include mesoporous-amorphous silica, ${ }^{5}$ mesoporousamorphous carbon ${ }^{6}$ and magnetic nanoparticles, ${ }^{7}$ etc. This is because they have unique properties, such as wide universality, cheap and easy to obtain raw materials, simple post-processing, and they are eco-friendly. At the same time, they have the advantage of being non-toxic and non-corrosive.

Therefore, a great amount of research has been devoted to a diverse range of biodegradable materials, such as xanthan sulfuric acid, ${ }^{8}$ starch sulfuric acid, ${ }^{9}$ sulfuric acid-modified PEG $\left(\mathrm{PEG}-\mathrm{SO}_{3} \mathrm{H}\right),{ }^{10-12}$ and meglumine ${ }^{13}$ which have been exploited as solid-support acid catalysts for acid-catalyzed transformations. Cellulose sulfonic acid (CSA) ${ }^{\mathbf{1 4}}$ is also the most interesting biosupport catalyst containing $-\mathrm{SO}_{3} \mathrm{H}$ and has been used in some organic synthesis conversions, such as cycloaddition, ${ }^{\mathbf{1 5}}$ diazotization, ${ }^{16}$ dehydration reaction, etc ${ }^{\mathbf{1 7 , 1 8}}$. However, the first preparation of cellulose sulfonic acid was reported by Ahmad. S., et al. ${ }^{14}$ The method is mainly through chlorosulfonic acid as a sulfonating reagent. Although this method is convenient and fast, it still has

State Key Laboratory of High-efficiency Utilization of Coal and Green Chemical Engineering, National Demonstration Center for Experimental Chemistry Education, College of Chemistry and Chemical Engineering, Ningxia University, Yinchuan 750021, P. R. China. E-mail: liuwy@nxu.edu.cn; Tel: +8613099519169

$\dagger$ Electronic supplementary information (ESI) available: Segmental details of the experimental procedures, the catalyst characterization results (HRTEM, IR, XRD, SEM, TEM, and TG), and the spectral data of the obtained compounds $\left({ }^{1} \mathrm{H}-\mathrm{NMR}\right.$ and $\left.{ }^{13} \mathrm{C}-\mathrm{NMR}\right)$ are shown in this file. See DOI: $10.1039 / \mathrm{c} 9 \mathrm{ra05748j}$

\$ These authors contributed equally in this work. certain limitations. For example, the prepared cellulose sulfonic acid has a lower acid value (the number of $\mathrm{H}^{+}$sites on the cellulose $-\mathrm{SO}_{3} \mathrm{H}$ was determined by acid-base titration to be $0.50 \mathrm{meq} \mathrm{g}^{-1}$ ); the chlorosulfonic acid is expensive and the use risk is increased; the catalyst is used in a large amount, and the catalytic reaction time is long. Rajitha. B., et al. ${ }^{19}$ and Javad. S., et al. ${ }^{20}$ used cellulose sulfonic acid as a catalyst for organic synthesis. Similarly, in these reaction processes, the reaction time is longer, the amount of the catalyst is large, and the cycle life is limited. Therefore, it is key to solve the above problems from the source to find a method capable of producing high quality, green, and durable cellulose sulfonic acid. It is worth noting that in this work we have made the process of synthesizing biomass-based solid sulfonic acids more environmentally friendly and green. In addition, the catalyst has excellent versatility and catalytic activity in catalytic organic synthesis, and also effectively avoids some disadvantages of conventional catalysts.

Dihydroquinazolinone and xanthene derivatives have very important applications as anticancer, ${ }^{21}$ anti-HIV, ${ }^{22}$ and antibacterial $^{23}$ agents etc. due to their good biological and pharmacological activities. At present, the main catalysts for the synthesis of dihydroquinazolinone derivatives include $\mathrm{I}_{2} /$ $\mathrm{DMF},{ }^{24}$ trifluoroacetic acid (TFA), ${ }^{25} \mathrm{InCl}_{3},{ }^{26} \mathrm{GO}$ nanosheets, ${ }^{27}$ etc. The xanthene derivative synthesis method mainly includes $\mathrm{Yb}(\mathrm{OTf})_{3}{ }^{28}$ cellulose sulfuric acid, ${ }^{29}\left[\mathrm{PVP}^{2} \mathrm{SO}_{3} \mathrm{H}\right] \mathrm{Cl},{ }^{30}$ etc. However, there are some disadvantages in the above catalytic synthesis methods. For example, the catalyst is expensive, the amount is large, and it is not easy to recycle; a large amount of toxic solvent is used; the reaction time is long and the yield is lower. Therefore, we still need to develop a more efficient, simple and green approach. 
We have developed a high acidity cellulose sulfate (HScellulose sulfate) as a biosupport catalyst by gas phase sulfonation of sulfur trioxide (as shown in Scheme 1). In addition, the heterogeneous catalyst is easy to prepare, insoluble in an organic solvent, easily separated from the reaction medium, has a high acid density and reactivity, and is more stable.

\section{Results and discussion}

\section{Characterization of HS-cellulose sulphate}

By analyzing the SEM photographs (Ce; CSA) before and after cellulose sulfonation (Fig. 1A and B), it was observed that Ce appeared as a relatively smooth micron-sized massive particle with obvious delamination and accumulation. The structure of CSA is characterized by relatively coarse micron-scale rods and a rough surface structure. This is attributed to sulfonation leading to modification of the cellulose surface structure and partial degradation of the linear polymer layer structure. In addition, the cellulose surface before and after sulfonation has no obvious pore structure, and the fiber width is about 3-10 $\mu \mathrm{m}$. It was observed by TEM (Fig. 1C) that the main layered structure of cellulose after sulfonation remained relatively intact, but the surface structure of the cellulose and the internal structure of the shallow layer changed to some extent. This is because the sulfonating agent $\mathrm{SO}_{3}$ interacts with the -OH group of cellulose, which not only generates new functional groups $\mathrm{C}-\mathrm{OSO}_{3} \mathrm{H}$, but also that adsorption of $\mathrm{SO}_{3}$ on the surface of cellulose leads to the formation of $\mathrm{H}_{2} \mathrm{SO}_{4}$ which then favours the partial degradation of the cellulose structure. In other words, the above mechanism of action is more favorable for the depolymerization of the cellulose layered structure and leads to rather modify the structure of the shallow layer of cellulose. In summary, we found that the $\mathrm{SO}_{3}$ gas sulfonation method not only changes the surface structure and functional groups of cellulose, but also contributes to the depolymerization of the internal structure of cellulose to some extent. In addition, it was observed by HRTEM (Fig. 1D) that cellulose sulfonic acid has a certain lattice spacing $(1.029 \mathrm{~nm}$ and $1.043 \mathrm{~nm}$, which is consistent with the literature $^{31}$ ), and different lattice fringes and crystal faces appear. This shows that the sulfonation of the sulfur trioxide gas phase not only uses a small amount of sulfonating agent and a controllable sulfonation reaction, but also obtains an acid site with an ordered surface structure while obtaining a sulfonate acid bond in the cellulose supermolecule. This structural trait makes it possible to be used as a highly efficient catalyst.

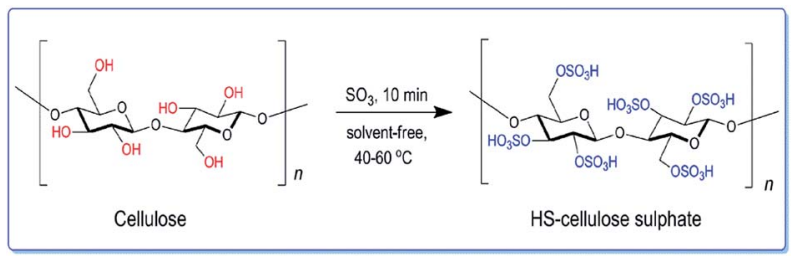

Scheme 1 Synthesis of HS-cellulose sulphate from $\alpha$-cellulose by $\mathrm{SO}_{3}$ gas.

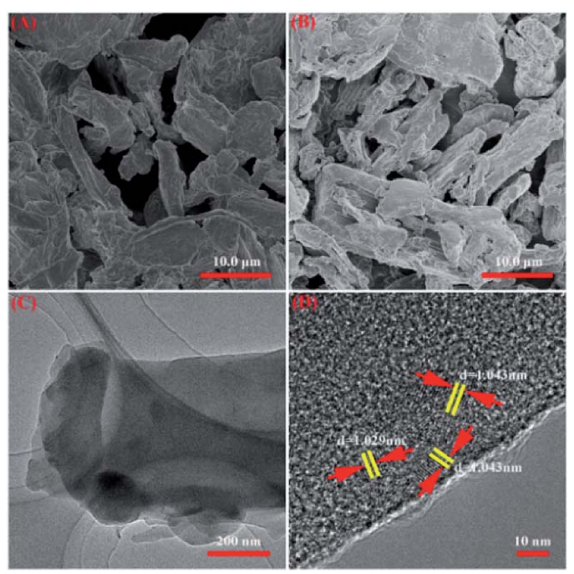

Fig. 1 SEM image of cellulose ( $\mathrm{Ce} ; \mathrm{A})$ and the fresh HS-cellulose sulphate (CSA; B). TEM and HRTEM image of fresh HS-cellulose sulphate $(C$ and $D)$.

By comparing the infrared spectra of CSA with different sulfonation times (shown as Fig. $2 a$ and $b$ ), we found that a longer sulfonation time means a deeper degree of depolymerization of the cellulose glucose unit, a more complex sulfonated product because of the formed sulfhydryl groups, and a deeper carbonization phenomenon (Fig. S1†). Therefore, we chose $10 \mathrm{~min}$ as the optimal sulfonation time. The IR spectrum (Fig. 2c) of the catalyst showed a broad peak for an $-\mathrm{O}-\mathrm{H}$ absorption band at the peaks at $3350 \mathrm{~cm}^{-1}$ and a $-\mathrm{CH}_{2}{ }^{-}$ absorption peak at $2898 \mathrm{~cm}^{-1}$. The peaks at 1114, 1062, and $898 \mathrm{~cm}^{-1}$ indicated C-O stretching, C-C skeletal vibration, and $\mathrm{C}-\mathrm{H}$ ring stretching of the glucose unit, respectively. ${ }^{32}$ Three new bands appeared in the IR spectrum at 1276, 1233 and $590 \mathrm{~cm}^{-1}$ corresponding to the $\mathrm{O}=\mathrm{S}=\mathrm{O}$ asymmetric and symmetric stretching vibrations and $\mathrm{S}-\mathrm{O}$ stretching vibration of the sulfonic acid groups. ${ }^{33}$ At the same time, the new peaks at $1721 \mathrm{~cm}^{-1}$ and $898 \mathrm{~cm}^{-1}$ are $\mathrm{C}=\mathrm{O}$ structural characteristic peaks, ${ }^{34}$ which means cellulose has been depolymerized slightly
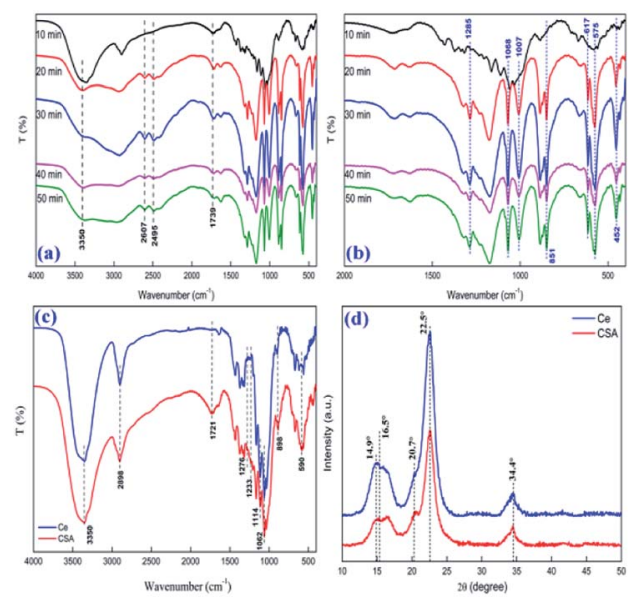

Fig. 2 FT-IR of different sulfonation times of cellulose (a) and (b); before and after sulfonation of cellulose ( $\mathrm{Ce}$ and CSA; ); and XRD of before and after sulfonation of cellulose (Ce and CSA; d). 
during sulfonation, and partially formed the structure of a polyhydroxyaldehyde or a polysulfonicaldehyde. ${ }^{35}$ It is worth noting that our method of synthesizing biomass-based solid sulfonic acid has a much higher sulphate content. From chemical titration and elemental analysis it was found that the number of $\mathrm{H}^{+}$sites on the cellulose- $\mathrm{SO}_{3} \mathrm{H}$ was $1.48 \mathrm{mmol} \mathrm{g}^{-1}$ and $1.55 \mathrm{mmol} \mathrm{g}^{-1}$, respectively.

The powder XRD pattern (Fig. 2d) of the matrix showed characteristic diffraction peaks for the cellulose eigenstate at $14.9^{\circ}, 22.5^{\circ}$ and $34.4^{\circ} .^{36}$ After sulfonation, HS-cellulose sulphate has two peaks at $16.5^{\circ}$ and $20.7^{\circ}$, respectively, in addition to the original peak shape. The small new peak indicates that the original crystal structure of cellulose has been damaged to some extent, but the original crystal structure is still retained. This corresponds to test results such as HRTEM. In summary, the results of these tests show that the catalyst has a unique structure.

To assess the thermal stability of HS-cellulose sulphate, TG experiments were carried out and are shown in Fig. 3. It can be seen from the thermogravimetric TG curve that the catalyst is roughly divided into four stages of weightlessness. The first stage loses weight from a small range of $92^{\circ} \mathrm{C}$ to $126^{\circ} \mathrm{C}$, and the weight loss is about $4.0 \%$. It is speculated that it may be the evaporation of physically adsorbed water on the surface of HScellulose sulphate. The second stage starts to lose weight quickly at around $121{ }^{\circ} \mathrm{C}$ until the weight loss is about $33.5 \%$ until $205{ }^{\circ} \mathrm{C}$. The analysis may be the sample-bonded sulfonic acid decomposition process; the third phase is a slow weight loss phase between $210{ }^{\circ} \mathrm{C}$ and $325{ }^{\circ} \mathrm{C}$, and the weight loss is about $15.1 \%$, which may be the depolymerization process of the cellulose polymer. The final stage is between $330-615{ }^{\circ} \mathrm{C}$, which could be attributed to the decomposition of cellulose. The weight losses found by the TG measurements agreed well with those anticipated for the decomposition of cellulose sulfonic acid to cellulose and the sulfonic acid group. The results show that the catalyst has good thermal stability.

\section{Catalytic performance evaluation of HS-cellulose sulphate from sulfur trioxide gas phase sulfonation}

First, we chose to synthesize dihydroquinazolinones as a model reaction to investigate the optimal conditions for the reaction

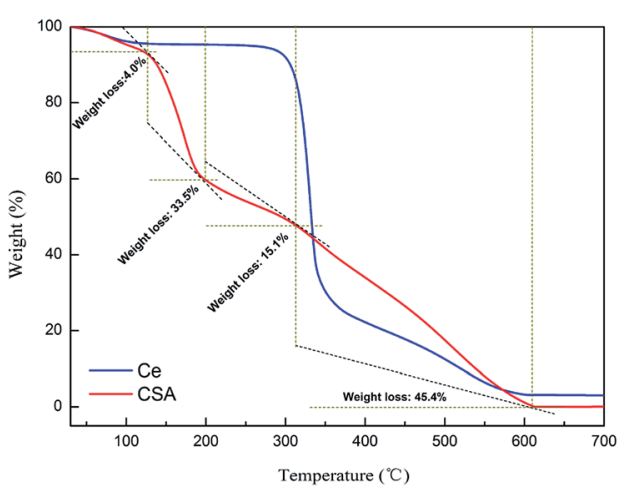

Fig. 3 TG analysis of cellulose (Ce) and HS-cellulose sulphate (CSA).
(Scheme 2). For most solvents, including water, the product is obtained in high yields at higher temperatures $\left(90{ }^{\circ} \mathrm{C}\right)$, indicating that the catalyst interacts well with the organic solvent (Table 1, entries 1-9), with the exception of DMSO. The amount of solvent used has a minor effect on the product yield of the model reaction (entries 10-12). It is worth noting that temperature has a large effect on the reaction, and the appropriate temperature significantly increases the product yield (entries 13-14). Increasing the amount of catalyst significantly increases product yield (entries 15-16). Based on the consideration of the green chemistry guidelines, we chose to use water as the solvent and use $10 \mathrm{mg}$ HS-cellulose sulphate catalyst at $60{ }^{\circ} \mathrm{C}$ for the most optimal reaction conditions.

To investigate the substrate range of the catalyst, we synthesized a series of dihydroquinazolinone derivatives (as shown in Table 2) using different aromatic aldehydes and 2aminobenzamide. The results show that both the electronwithdrawing and aromatic aldehydes of the electron-donating group can participate in the reaction, and a good yield can be obtained (Table 2, entries 1-18). Although the corresponding yield of $p$-phenylbenzaldehyde is low, it can also reach $80 \%$ (entry 7) due to the electronic effect of the substituents. It is important that the acid-labile substrates, such as $p$-dimethylaminobenzaldehyde, also yield good yields of the desired product (entry 3). This is very significant. The thiophenecarbaldehyde can also react well with 2-aminobenzamide to give good yields (entry 14). It is worth noting that 2-aminobenzamides with different substituents react with aromatic aldehydes to produce unique effects (entries 15-20). Among them, 4-nitro-2-aminobenzamide has the best effect, while the 5-Cl and 5- $\mathrm{OCH}_{3}$ substituents are not effective (entries 19-20). In general, the HS-cellulose sulphate catalyst is excellent in catalyzing the synthesis of dihydroquinazolinone derivatives.

To further investigate the universality of the catalyst HScellulose sulphate, we synthesized a series of xanthene compounds by using Scheme 3 as a model reaction. Through conditional screening, the optimal conditions for the model reaction are determined (Table $\mathrm{S} 1, \dagger$ entry 4 ). It was confirmed that the reaction was carried out under heating without a solvent. Almost all aromatic aldehydes can be reacted with 2-naphthol in the absence of solvent to form the corresponding xanthene derivatives, which is very valuable (Table 3 , entries 1-21). The advantage is that the catalyst is used in a small amount ( $10 \mathrm{mg}, 4.0 \mathrm{mmol} \%)$, the reaction time is short (1.0-1.5 h), and the yield of all target compounds is as high as $94 \%$ or more (entries $1-14$ ). It is noteworthy that acetaldehyde and propionaldehyde can also react with 2-naphthol to produce the target product with yields of $76 \%$ and 80\% (entry 15 and 16), respectively. Similarly, 2-naphthol with

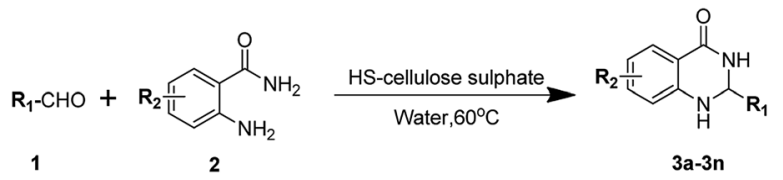

Scheme 2 HS-cellulose sulfate catalytic synthesis of dihydroquinazolinones. 
Table 1 Optimization of conditions for the synthesis of the quinazolinone reaction using the HS-cellulose sulphate catalyst

\begin{tabular}{lllll}
\hline Entry $^{a}$ & Catalyst/mg & Temperature $/{ }^{\circ} \mathrm{C}$ & Solvent & Yield $^{b} / \%$ \\
\hline 1 & 1 & 90 & Ethanol & 98 \\
2 & 1 & 90 & Methanol & 97 \\
3 & 1 & 90 & IPA & 94 \\
4 & 1 & 90 & DCE & 99 \\
5 & 1 & 90 & DMSO & 60 \\
6 & 1 & 90 & THF & 98 \\
7 & 1 & 90 & Ethyl acetate & 96 \\
8 & 1 & 90 & Acetonitrile & 96 \\
9 & 1 & 90 & Water & 98 \\
$10^{c}$ & 10 & 60 & Water & 82 \\
$11^{d}$ & 10 & 60 & Water & 92 \\
$12^{e}$ & 10 & 60 & Water & 90 \\
13 & 1 & 60 & Water & 46 \\
14 & 1 & 30 & Water & 12 \\
15 & 5 & 60 & Water & 75 \\
$\mathbf{1 6}$ & $\mathbf{1 0}$ & $\mathbf{6 0}$ & Water & $\mathbf{9 9}$
\end{tabular}

${ }^{a}$ Reaction conditions: aldehyde $(0.5 \mathrm{mmol}), 2$-aminobenzamide $(0.5$ $\mathrm{mmol}$ ), catalyst: HS-cellulose sulfate; solvent dosage: $1.5 \mathrm{~mL}$; IPA: isopropanol. DCE: dichloroethane. THF: tetrahydrofuran. ${ }^{b}$ Isolated yield. ${ }^{c}$ The solvent dosage is $0.5 .{ }^{d}$ The solvent dosage is $1.0 \mathrm{~mL}$. ${ }^{e}$ The solvent dosage is $2.0 \mathrm{~mL}$.

different substituents reacts with aromatic aldehydes to produce different effects (entries 17-24). The effect obtained with 6-Brnaphthol is better (entries 17-21), while the $1-\mathrm{Br}, 8-\mathrm{NH}_{2}$ and 6$\mathrm{COOH}$ substituents are not effective (entries 22-24).

Table 2 HS-cellulose sulfate catalyzed synthesis of dihydroquinazolinones derivatives in water

\begin{tabular}{|c|c|c|c|c|c|}
\hline Entry $^{a}$ & $\mathrm{R}_{1}$ & $\mathrm{R}_{2}$ & Pro & Time (h) & Yield $^{b}(\%)$ \\
\hline 1 & $-\mathrm{C}_{6} \mathrm{H}_{5}$ & $\mathrm{H}$ & $3 \mathbf{a}$ & 0.7 & $94(90,88,82)^{c}$ \\
\hline 2 & $4-\mathrm{CH}_{3}-\mathrm{C}_{6} \mathrm{H}_{4}$ & $\mathrm{H}$ & $3 \mathbf{b}$ & 1.5 & 87 \\
\hline $3^{d}$ & $4-\mathrm{N}\left(\mathrm{CH}_{3}\right)_{2}-\mathrm{C}_{6} \mathrm{H}_{4}$ & $\mathrm{H}$ & $3 \mathbf{c}$ & 1.5 & 98 \\
\hline 4 & $4-\mathrm{OCH}_{3}-\mathrm{C}_{6} \mathrm{H}_{4}$ & $\mathrm{H}$ & $3 d$ & 1.0 & 86 \\
\hline 5 & $4-\mathrm{NO}_{2}-\mathrm{C}_{6} \mathrm{H}_{4}$ & $\mathrm{H}$ & $3 e$ & 1.0 & 87 \\
\hline 6 & $4-\mathrm{COOH}-\mathrm{C}_{6} \mathrm{H}_{4}$ & $\mathrm{H}$ & $3 f$ & 2.0 & 91 \\
\hline $7^{d}$ & $4-\mathrm{C}_{6} \mathrm{H}_{5}-\mathrm{C}_{6} \mathrm{H}_{4}$ & $\mathrm{H}$ & $3 g$ & 2.0 & 80 \\
\hline 8 & $4-\mathrm{F}-\mathrm{C}_{6} \mathrm{H}_{4}$ & $\mathrm{H}$ & $3 \mathbf{h}$ & 1.0 & 89 \\
\hline $9^{d}$ & $4-\mathrm{Br}-\mathrm{C}_{6} \mathrm{H}_{4}$ & $\mathrm{H}$ & $3 \mathbf{i}$ & 1.5 & 85 \\
\hline $10^{d}$ & $4-\mathrm{Cl}-\mathrm{C}_{6} \mathrm{H}_{4}$ & $\mathrm{H}$ & $3 \mathbf{j}$ & 1.5 & 92 \\
\hline 11 & $2-\mathrm{Cl}-\mathrm{C}_{6} \mathrm{H}_{4}$ & $\mathrm{H}$ & $3 \mathbf{k}$ & 2.0 & 98 \\
\hline 12 & $3-\mathrm{Cl}-\mathrm{C}_{6} \mathrm{H}_{4}$ & $\mathrm{H}$ & 31 & 2.0 & 83 \\
\hline 13 & $4-\mathrm{OH}-3-\mathrm{OCH}_{3}-\mathrm{C}_{6} \mathrm{H}_{4}$ & $\mathrm{H}$ & $3 \mathbf{m}$ & 1.0 & 95 \\
\hline 14 & $-\mathrm{C}_{4} \mathrm{H}_{3} \mathrm{~S}$ & $\mathrm{H}$ & $3 n$ & 2.0 & 88 \\
\hline 15 & $-\mathrm{C}_{6} \mathrm{H}_{5}$ & $4-\mathrm{NO}_{2}$ & 30 & 1.5 & 91 \\
\hline 16 & $4-\mathrm{CH}_{3}-\mathrm{C}_{6} \mathrm{H}_{5}$ & $4-\mathrm{NO}_{2}$ & $3 \mathbf{p}$ & 1.5 & 90 \\
\hline 17 & $4-\mathrm{Cl}-\mathrm{C}_{6} \mathrm{H}_{5}$ & $4-\mathrm{NO}_{2}$ & $3 q$ & 1.5 & 89 \\
\hline 18 & $2-\mathrm{Cl}-\mathrm{C}_{6} \mathrm{H}_{5}$ & $4-\mathrm{NO}_{2}$ & $3 \mathbf{r}$ & 2.0 & 92 \\
\hline 19 & $-\mathrm{C}_{6} \mathrm{H}_{5}$ & $5-\mathrm{Cl}$ & $3 s$ & 6.0 & N.R \\
\hline 20 & $-\mathrm{C}_{6} \mathrm{H}_{5}$ & $5-\mathrm{OCH}$ & $3 t$ & 6.0 & Trace \\
\hline
\end{tabular}

${ }^{a}$ Reaction conditions: aromatic aldehyde $(0.5 \mathrm{mmol})$, aminobenzamide $(0.5 \mathrm{mmol})$, HS-cellulose sulphate $(10 \mathrm{mg}), 60^{\circ} \mathrm{C}$; water $(1.5 \mathrm{~mL})$. The reactions were run until completion as indicated by TLC. N.R: no reaction. All the compounds are known, characterized by ${ }^{1} \mathrm{H}$ NMR and ${ }^{13} \mathrm{C}$ NMR. ${ }^{b}$ Isolated yield. ${ }^{c}$ The recovered catalyst cycle yield. ${ }^{d}$ The solvent was water : ethanol $=1: 1$.

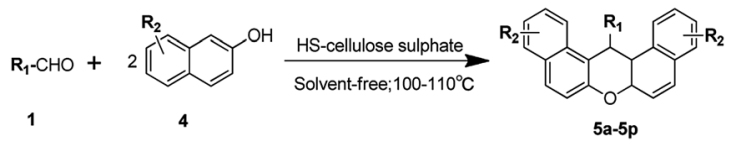

Scheme 3 HS-cellulose sulfate catalytic synthesis of xanthene compounds.

Similarly, one of the evaluation criteria for the efficient use of catalysts is whether the catalyst can be recycled. We examined the cyclical use of both model reactions for the HS-cellulose sulphate catalyst synthesis (Table 2, entry 1 and Table 3, entry 1). The results show that the HS-cellulose sulphate catalyst can be recycled in two reaction systems. Although the yield of the target product decreased after the catalyst was recycled 3 times, it was still able to maintain a yield of more than $80 \%$, which is fortunate. The deactivation of the HS-cellulose sulphate catalyst is due to several possibilities. One is that during the catalytic process, the catalyst is not collected due to the small amount of the catalyst. The second is that the sulfonic acid group is a hydrophilic group, and the water formed during the reaction dissolves part of the catalyst, resulting in deactivation of the catalyst. Similarly, we have shown from the results of the infrared and elemental analysis (Fig. S2 and Table S2 $\dagger$ ) that the catalyst has a certain loss during use, and the $\mathrm{S}$ content ratio in

Table 3 The HS-cellulose sulphate catalyzed synthesis of xanthene compounds under solvent-free conditions

\begin{tabular}{|c|c|c|c|c|c|}
\hline Entry $^{a}$ & $\mathrm{R}_{1}$ & $\mathrm{R}_{2}$ & Product & Time (h) & Yield $^{b}(\%)$ \\
\hline 1 & $-\mathrm{C}_{6} \mathrm{H}_{5}$ & $\mathrm{H}$ & $5 a$ & 1.0 & $97(94,89,86)^{c}$ \\
\hline 2 & $4-\mathrm{NO}_{2}-\mathrm{C}_{6} \mathrm{H}_{4}$ & $\mathrm{H}$ & $5 \mathbf{b}$ & 1.0 & 98 \\
\hline 3 & $3-\mathrm{NO}_{2}-\mathrm{C}_{6} \mathrm{H}_{4}$ & $\mathrm{H}$ & $5 c$ & 1.0 & 97 \\
\hline 4 & $4-\mathrm{Br}-\mathrm{C}_{6} \mathrm{H}_{4}$ & $\mathrm{H}$ & $5 d$ & 1.0 & 97 \\
\hline 5 & $2-\mathrm{Br}-\mathrm{C}_{6} \mathrm{H}_{4}$ & $\mathrm{H}$ & $5 e$ & 1.0 & 94 \\
\hline 6 & $3-\mathrm{Br}-\mathrm{C}_{6} \mathrm{H}_{4}$ & $\mathrm{H}$ & $5 f$ & 1.0 & 95 \\
\hline 7 & $4-\mathrm{Cl}-\mathrm{C}_{6} \mathrm{H}_{4}$ & $\mathrm{H}$ & $5 g$ & 1.0 & 97 \\
\hline 8 & $3-\mathrm{Cl}-\mathrm{C}_{6} \mathrm{H}_{4}$ & $\mathrm{H}$ & $5 \mathrm{~h}$ & 1.0 & 94 \\
\hline 9 & $2-\mathrm{Cl}-\mathrm{C}_{6} \mathrm{H}_{4}$ & $\mathrm{H}$ & $5 \mathbf{i}$ & 1.1 & 96 \\
\hline 10 & 4-CN- $\mathrm{C}_{6} \mathrm{H}_{4}$ & $\mathrm{H}$ & $5 \mathbf{j}$ & 1.0 & 97 \\
\hline 11 & $4-\mathrm{F}-\mathrm{C}_{6} \mathrm{H}_{4}$ & $\mathrm{H}$ & $5 k$ & 1.0 & 96 \\
\hline 12 & $4-\mathrm{C}_{6} \mathrm{H}_{5}-\mathrm{C}_{6} \mathrm{H}_{4}$ & $\mathrm{H}$ & 51 & 1.5 & 95 \\
\hline 13 & $4-\mathrm{CH}_{3}-\mathrm{C}_{6} \mathrm{H}_{4}$ & $\mathrm{H}$ & $5 m$ & 1.5 & 94 \\
\hline 14 & $2,4-\mathrm{Cl}_{2}-\mathrm{C}_{6} \mathrm{H}_{3}$ & $\mathrm{H}$ & $5 n$ & 1.5 & 95 \\
\hline 15 & $-\mathrm{C}_{3} \mathrm{H}_{7}$ & $\mathrm{H}$ & 50 & 1.5 & 80 \\
\hline 16 & $-\mathrm{C}_{2} \mathrm{H}_{5}$ & $\mathrm{H}$ & $5 p$ & 1.5 & 76 \\
\hline 17 & $-\mathrm{C}_{6} \mathrm{H}_{5}$ & $6-\mathrm{Br}$ & $5 q$ & 2.0 & 80 \\
\hline 18 & $4-\mathrm{CH}_{3}-\mathrm{C}_{6} \mathrm{H}_{5}$ & $6-\mathrm{Br}$ & $5 r$ & 2.0 & 84 \\
\hline 19 & $4-\mathrm{F}-\mathrm{C}_{6} \mathrm{H}_{5}$ & $6-\mathrm{Br}$ & $5 s$ & 2.5 & 68 \\
\hline 20 & $4-\mathrm{Cl}-\mathrm{C}_{6} \mathrm{H}_{5}$ & $6-\mathrm{Br}$ & $5 t$ & 2.0 & 80 \\
\hline 21 & $3-\mathrm{Br}-\mathrm{C}_{6} \mathrm{H}_{5}$ & $6-\mathrm{Br}$ & $5 \mathbf{u}$ & 1.5 & 91 \\
\hline 22 & $-\mathrm{C}_{6} \mathrm{H}_{5}$ & $1-\mathrm{Br}$ & $5 v$ & 6.0 & N.R \\
\hline 23 & $-\mathrm{C}_{6} \mathrm{H}_{5}$ & $8-\mathrm{NH}_{2}$ & $5 w$ & 6.0 & Trace \\
\hline 24 & $-\mathrm{C}_{6} \mathrm{H}_{5}$ & 6- $\mathrm{COOH}$ & $5 x$ & 6.0 & Trace \\
\hline
\end{tabular}

${ }^{a}$ Reaction conditions: aromatic aldehyde $(1.0 \mathrm{mmol}), 2$-naphthol (1.0 mmol), HS-cellulose sulphate $(10 \mathrm{mg})$, and $100-110{ }^{\circ} \mathrm{C}$. The reactions were run until completion as indicated by TLC. N.R: no reaction. All the compounds are known, characterized by ${ }^{1} \mathrm{H}$ NMR and ${ }^{13} \mathrm{C}$ NMR. ${ }^{b}$ Isolated yield. ${ }^{c}$ The recovered catalyst cycle yield. 
the catalyst drops from the initial $4.65 \%$ to $1.64 \%$. This ultimately leads to a decrease in activity after the catalysts are used three times.

The high efficiency catalysis and multiple cycle performance of the HS-cellulose sulphate catalyst has a very important relationship with the structure of the catalyst itself. After the $\alpha$ cellulose is sulfonated with liquid $\mathrm{SO}_{3}$, its original cellulose surface structure is destroyed, and a large amount of the $-\mathrm{SO}_{3} \mathrm{H}$ groups are present on the surface, while a part of the cellulose sulfonate appears. It has abundant catalytic active groups and dispersed active sites and stability properties after being sulfonated for $10 \mathrm{~min}$, whether it is the surface structure of the catalyst or the acidity value of the material. Just as mentioned above, significant lattice streaks on the surface of the material are a novel nano-scale catalyst formed by sulfur trioxide gas phase sulfonation of $\alpha$-cellulose. The structure-activity relationship of this nanomaterial has rarely been reported before.

\section{Experimental section}

\section{Preparation of HS-cellulose sulphate from sulfur trioxide gas phase sulfonation}

The generation of sulfur trioxide and its sulfonation reaction were carried out in a $250 \mathrm{~mL}$ three-neck flask with a graduated Soxhlet extractor and a gas absorption device. In advance, in the Soxhlet extractor with a diameter of about $4 \mathrm{~cm}$, the filled glass beads $(0.5-1.0 \mathrm{~cm}$ in diameter) are coated with about $1 \mathrm{~cm}$ thick cellulose powder with about $0.5 \mathrm{~cm}$ (about $0.5 \mathrm{~g}$ ). In turn, a total of $2 \mathrm{~g}$ cellulose powder and glass beads were added. Then 10$20 \mathrm{~g}$ phosphorus pentoxide was added to the flask. At room temperature, concentrated sulfuric acid of 20-30 mL was added by a constant pressure drop funnel, and about $10 \mathrm{~min}$ drops were slowly heated to three bottles. Heating to about $180{ }^{\circ} \mathrm{C}$, sulfur trioxide gas enters the upper end smoothly from the side of the Soxhlet extractor, and naturally condenses to $40-45{ }^{\circ} \mathrm{C}$ and flows into the filled fiber material. At this time, the sulfur trioxide sulfonation reaction begins.

After sulfonation, 10-20 min, the total approaching $1 \mathrm{~mL}$ of liquid sulfur trioxide was collected and three bottle heating kits were removed (Fig. 4). The reaction material was removed into a beaker, $10 \mathrm{~mL}$ of water was added to soak, and the mixture was then filtered and washed with $4 \times 10 \mathrm{~mL}$ deionized water and followed by vacuum drying $\left(50{ }^{\circ} \mathrm{C}, 24 \mathrm{~h}\right.$ ) to afford $2.8 \mathrm{~g}$ of HScellulose sulphate as a pale yellow powder. The number of $\mathrm{H}^{+}$ sites on the cellulose- $\mathrm{SO}_{3} \mathrm{H}$ was determined by acid-base titration to be $1.48 \mathrm{mmol} \mathrm{g}^{-1}$, while the sulfur content of the samples was $1.55 \mathrm{mmol} \mathrm{g}^{-1}$ as judged by conventional elemental analysis. The similarity between these two values indicated that most of the sulfur species in the sample were part of the sulfonic acid groups. The elemental sulphur content of HS-cellulose sulphate indicated a comparatively much higher sulphate content in the sulfur trioxide-derived HS-cellulose.

\section{Procedure for the synthesis of the xanthene compounds}

A mixture of 2-naphthol (2 mmol) and aromatic aldehyde (1 $\mathrm{mmol}$ ) was heated and stirred at $110{ }^{\circ} \mathrm{C}$ in a chicken heart

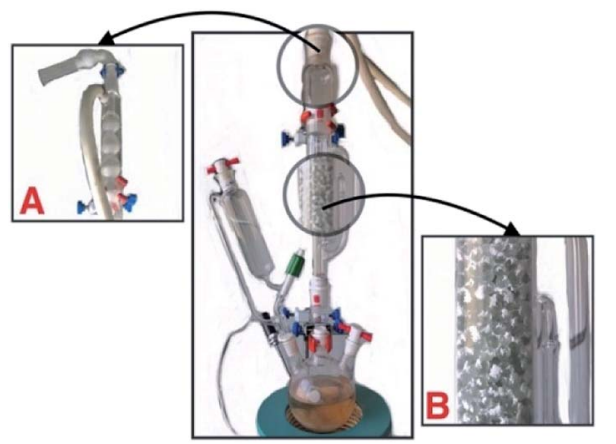

Fig. 4 The gas phase sulfonation equipment from sulfur trioxide. ((A) The spherical condenser and exhaust gas absorption device (cotton and $\mathrm{KOH}$ ). (B) The cellulose mixed with glass beads.)

bottle. Then, HS-cellulose sulphate (10 mg, $4.0 \mathrm{mmol} \%$ ) was added to it. The resulting mixture was stirred magnetically at 110-115 ${ }^{\circ} \mathrm{C}$, and after solidification of the reaction mixture and also at the same temperature, it was vigorously stirred with a small rod. After completion of the reaction, as monitored by TLC, the reaction mixture was cooled to room temperature, and the EtOAc $(2 \times 3 \mathrm{~mL})$ was added. The cellulose sulfuric acid was filtered off and collected for the next reaction. The filtrate was concentrated to dryness, and the crude solid product was crystallized from EtOH to afford the pure xanthene compounds. All compound structures were analyzed by ${ }^{1} \mathrm{H}$-NMR and ${ }^{13} \mathrm{C}-\mathrm{NMR}$.

\section{Procedure for the synthesis of the dihydroquinazolinone derivatives}

The aminobenzamide $(0.5 \mathrm{mmol})$, HS-cellulose sulphate (10 $\mathrm{mg})$, water $1.5 \mathrm{~mL}$, and aldehyde $(0.5 \mathrm{mmol})$ were separately added to a Schlenk tube and stirred with heating at $60{ }^{\circ} \mathrm{C}$ until the end of the reaction (TLC was used to follow the reaction). The ethanol $(2 \times 3 \mathrm{~mL})$ was added to the reaction system, and the catalyst was collected for the next reaction by simple filtration. The filtrate was concentrated and subjected to column chromatography (with an eluent ratio of petroleum ether : ethyl acetate of $1: 1$ ) and purified. All compound structures were analyzed by ${ }^{1} \mathrm{H}-\mathrm{NMR}$ and ${ }^{13} \mathrm{C}-\mathrm{NMR}$.

\section{Conclusions}

The application of a high acidity cellulose sulfuric acid catalyst (HS-cellulose sulfonate) prepared from sulfur trioxide provides new ideas and methods for green organic synthesis. In particular, as a kind of sulfonated biomass-based solid acid catalyst, it proves to be an efficient catalyst for the synthesis of pharmaceutical intermediate quinolinone in water and xanthene derivatives in solvent-free conditions. The excellent catalytic performance and stability of HS-cellulose sulfonate depend on the specific sulfonation of cellulose which has a large effect on its matrix structure. Further depolymerization and reorganization of the cellulose structure provides the possibility of deep sulfonation of cellulose in gas sulfur trioxide, which is also 
responsible for the acidity value of up to $1.55 \mathrm{mmol} \mathrm{g}^{-1}$ and as an environmentally friendly catalyst.

\section{Conflicts of interest}

The authors declare no competing financial interest.

\section{Acknowledgements}

This work was supported by the Major Innovation Projects for Building First-class Universities in China's Western Region (No. ZKZD2017003), the National First-rate Discipline Construction Project of Ningxia (No. NXYLXK 2017A04) and the National Natural Science Foundation of China (No. 21862013).

\section{Notes and references}

1 Z. Daneshfar and A. Rostami, RSC Adv., 2015, 5, 104695104707.

2 S. S. Dachavaram, N. R. Penthala, J. L. Calahan, E. J. Munson and P. A. Crooks, Org. Biomol. Chem., 2018, 16, 6057-6062.

3 W. Cai, Q. Chen, H. Xuan, C. Li, H. Yu, L. Cui, Z. Yu, S. Zhang and F. Qu, Korean J. Chem. Eng., 2019, 36, 513-521.

4 J. Pan, H. Gao, Y. Zhang, J. Zeng, W. Shi, C. Song, Y. Yan, L. Yu and D. Chang, RSC Adv., 2014, 4, 59175-59184.

5 B. Zhou, J. Yang, M. Li and Y. Gu, Green Chem., 2011, 13, 2204-2211.

6 K. Nakajima and M. Hara, ACS Catal., 2012, 2, 1296-1304.

7 B. Akhlaghinia, P. Sanati, A. Mohammadinezhad and Z. Zarei, Res. Chem. Intermed., 2019, 45, 3215-3235.

8 A. Shaabani, A. Maleki, M. Soudi and H. Mofakham, Catal. Commun., 2009, 10, 945-949.

9 A. Shaabani, A. Rahmati and Z. Badri, Catal. Commun., 2008, 9, 13-16.

10 A. Hasaninejad, A. Zare, M. Shekouhy and J. Ameri-Rad, Green Chem., 2011, 13, 958-964.

11 S. Paul and A. R. Das, Tetrahedron Lett., 2013, 54, 1149-1154.

12 R. H. Vekariya and H. D. Patel, RSC Adv., 2015, 5, 4900649030.

13 R. Y. Guo, Z. M. An, L. P. Mo, S. T. Yang, H. X. Liu, S. X. Wang and Z. H. Zhang, Tetrahedron, 2013, 69, 9931-9938.

14 A. Shaabani and A. Maleki, Appl. Catal., A, 2007, 331, 149151.

15 D. R. Merchan Arenas and V. V. Kouznetsov, J. Org. Chem., 2014, 79, 5327-5333.
16 F. Nemati and A. L. I. Elhampour, J. Chem. Sci., 2012, 124, 889-892.

17 B. Liu, Z. Zhang and K. Huang, Cellulose, 2013, 20, 20812089.

18 A. Shrotri, H. Kobayashi and A. Fukuoka, Acc. Chem. Res., 2018, 51, 761-768.

19 J. Venu Madhav, Y. Thirupathi Reddy, P. Narsimha Reddy, M. Nikhil Reddy, S. Kuarm, P. A. Crooks and B. Rajitha, J. Mol. Catal. A: Chem., 2009, 304, 85-87.

20 J. Safari, S. H. Banitaba and S. D. Khalili, J. Mol. Catal. A: Chem., 2011, 335, 46-50.

21 G. Grover and S. G. Kini, Eur. J. Med. Chem., 2006, 41, 256262.

22 V. Alagarsamy, R. Giridhar, K. Dhanabal, M. Murugan and E. De Clercq, Indian J. Pharm. Sci., 2007, 69, 34.

23 T. Nishiyama, K. Sakita, T. Fuchigami and T. Fukui, Polym. Degrad. Stab., 1998, 62, 529-534.

24 B. A. Bhat and D. P. Sahu, Synth. Commun., 2004, 34, 21692176.

25 X. Yang, G. Cheng, J. Shen, C. Kuai and X. Cui, Org. Chem. Front., 2015, 2, 366-368.

26 N. Mulakayala, B. Kandagatla, Ismail, R. K. Rapolu, P. Rao, C. Mulakayala, C. S. Kumar, J. Iqbal and S. Oruganti, Bioorg. Med. Chem. Lett., 2012, 22, 5063-5066.

27 N. Kausar, I. Roy, D. Chattopadhyay and A. R. Das, RSC Adv., 2016, 6, 22320-22330.

28 W. Su, D. Yang, C. Jin and B. Zhang, Tetrahedron Lett., 2008, 49, 3391-3394.

29 S. Maddila, M. Momin, P. Lavanya and C. V. Rao, J. Saudi Chem. Soc., 2016, 20, 173-177.

30 F. Shirini, P. N. Moghadam, S. Moayedi and M. Seddighi, RSC Adv., 2014, 4, 38581-38588.

31 R. J. Moon, A. Martini, J. Nairn, J. Simonsen and J. Youngblood, Chem. Soc. Rev., 2011, 40, 3941-3994.

32 D. Ciolacu, F. Ciolacu and V. I. Popa, Cellul. Chem. Technol., 2011, 45, 13-21.

33 S. M. Chackalackal and F. E. Stafford, J. Am. Chem. Soc., 1966, 88, 4815-4819.

34 D. Rajalaxmi, N. Jiang, G. Leslie and A. J. Ragauskas, Carbohydr. Res., 2010, 345, 284-290.

35 O. D. E. Gebauer-Fuelnegg, J. Am. Chem. Soc., 1930, 52, 28492854.

36 Y. Wu, Z. Fu, D. Yin, Q. Xu, F. Liu, C. Lu and L. Mao, Green Chem., 2010, 12, 696-700. 